analecta polit. | Vol. 10 | No. 18 | PP. 36-58

| enero-junio | 2020 | ISSN-e: 2390-0067 (en línea) | Medellín-Colombia

doi: http://dx.doi.org/10.18566/apolit.v10n18.a03

\title{
Uso bélico de las normas penales en Colombia \\ (1962-1980): arma estatal \\ para derrotar al enemigo*
}

\begin{abstract}
War Use of Criminal Laws in Colombia (1962-1980): A State Weapon to Defeat the Enemy
\end{abstract}

Cómo citar

este artículo en APA:

Arbeláez Villegas, L.

C. (2020). Uso bélico

de las normas penales

en Colombia (1962-

1980): arma estatal para

derrotar al enemigo.

Analecta Política, 10(18),

36-58.
Fecha de recepción:

18.09.2019

Fecha de aceptación:

17.01.2020

\section{LUIS CARLOS ARBELÁEZ VILLEGAS}

Magíster en Estudios Políticos Universidad Pontificia Bolivariana

Correo: luis.arbelaez@upb.edu.co

* Producto adscrito al proyecto de investigación "Discurso y prácticas políticas en el marco del pluralismo democrático" Radicado: 955B-12/17-36. Centro de Investigación para el Desarrollo y la Investigación (CIDI). Universidad Pontificia Bolivariana. 


\section{Resumen}

Este texto aborda el problema de la utilización de la legislación penal colombiana como un arma para restablecer el orden y combatir a un enemigo impreciso y variable. Se aborda específicamente el período comprendido entre los años 1962 y 1980, en el cual el enemigo cambia del liberal ateo al guerrillero comunista. La expedición del Código Penal de 1980 concreta finalmente la preferencia por el castigo en la historia reciente de Colombia como la opción más calificada para responder al fenómeno de la violencia, para lograr la "salvación nacional" o simplemente para recuperar o mantener el orden social e institucional. Posiblemente esa opción del poder político por la solución penal sea una alternativa simple, irracional o inconsulta o, en todo caso, una opción por un uso bélico de las normas penales, que desde sus comienzos evitó cualquier recomendación experta. Por eso el texto examina el peso de la Comisión Investigadora de las Causas y Situaciones Presentes de la Violencia cuyo diagnóstico sobre el uso del derecho penal se encontraba vigente en aquel período.

Palabras clave: Política criminal, expertos, instituciones penales, guerra.

\section{Abstract}

The present text addresses the issue of the use of criminal laws as a weapon to restore order and to combat an imprecise and variable enemy, specifically during the period 1962-1980. During this period, the enemy changes from being the liberal atheist to the communist guerrilla man. The issuing of the Penal Code of 1980 ultimately determines the preference for punishment in the history of Colombia as the most qualified answer to the issue of violence to achieve "national salvation", or simply to recover or maintain the institutional and social order. Possibly, the option of political power through the penal solution is a simple and irrational alternative or, in any case, the option for the war use of the penal norms that, from the beginning, evaded any expert advice. Therefore, this article investigates the value of the Comisión Investigadora de las Causas y Situaciones Presentes de la Violencia (Investigative commission for the causes and present state of violence), whose diagnose of the use of the Penal Code was valid during such period.

Key Words: Criminal law, experts, penal institutions, war. 


\section{Introducción}

El presente artículo se ocupa especialmente de la incidencia de la Comisión Investigadora de las Causas Actuales de la Violencia en las discusiones y legislación penal que precedieron la expedición del Código Penal (CP) de 1980. En el proceso seguido para alcanzar dicho objetivo se analizó el diagnóstico y las recomendaciones de la Investigadora en $1958^{1}$ y se contrastó con una serie importante de normas en materia penal —un total de 36 normas, algunas están recogidas en este texto a manera de ejemplo_ que fueron expedidas entre 1962 y 1980.

Cuando se alude a instituciones políticas entendemos que estas son un foco importante en la actividad política, aquel "patrón de conducta recurrente, valioso y estable" (Goodin, 2003), que se materializan en reglas de juego con las que "se encauzan las interacciones de los actores políticos que permiten prever desarrollos futuros y que colaboran sustancialmente en la solución de conflictos" (Losada y Casas, 2008, p. 163). Es importante anotar la relevancia que adquieren las comisiones de expertos en el diseño de esas reglas de juego en materia de política criminal, dado que el diseño institucional genera restricciones que afectan el comportamiento del individuo y regulan su conducta a través del uso de reglas explícitas por un grupo de actores que son reconocidos por tener ese poder (Levi, 1990), además de que responden a una situación o contexto determinado, en este caso por el conflicto y la guerra.

El contexto bélico en Colombia ha permitido que la guerra incida en el diseńo y uso de las instituciones, o expresado de otra manera, "la guerra y no solo el derecho ha incidido en la manera como las instituciones políticas son creadas y utilizadas en un contexto de confrontación armada" (Muñoz, 2014, p. 157). En síntesis, este artículo aborda la incidencia de las recomendaciones y el diagnóstico de los expertos mencionados en el diseño de instituciones penales en Colombia en el período comprendido entre 1962 y 1980, cuando grupos armados conformados para instituir un nuevo orden, subvirtiendo el que consideraban injusto o inadecuado, le disputaban al Estado - como ocurre actualmente- su control de territorios y personas. Estos fueron catalogados como enemigos y, entre otros mecanismos, el Estado buscó combatirlos por medio de las normas penales.

1 En adelante se denominará así a la Comisión Investigadora de las Causas Actuales de la Violencia siguiendo la denominación utilizada por Jefferson Jaramillo Marín (2011). 


\section{Colombia: un país marcado por la violencia y un Estado urgido por garantizar su gobernabilidad bajo el uso bélico de las normas penales}

Colombia atravesó a finales de los años cuarenta e inicios de los cincuenta una crisis política que enfrentó a los partidos tradicionales - Liberal y Conservador-. La contienda no solo fue electoral, sino también armada. La lucha bipartidista en Colombia se desarrolló entre facciones de los partidos políticos liberal y conservador por el control del Estado. Después de todo, "en esta lucha ambas partes tuvieron la posibilidad de declarar la guerra a su contrario, influyendo en la mentalidad de los ciudadanos, arrastrándolos a niveles de violencia e intolerancia que posteriormente fueron incontrolables" (Puerta, 2008, p. 193). La identificación del otro, del enemigo, empieza a definir "dos campos excluyentes y confrontados entre amigos y enemigos, donde no fue posible establecer un terreno común de identidad ciudadana y sentido de pertenencia nacional" (Uribe, 1995, pp. 45-46). En ese contexto, ya la persecución política por parte de los conservadores había fundado las bases de la organización guerrillera liberal ${ }^{2}$. Más adelante, la exclusión y persecución del Estado, y algunas influencias externas (como el triunfo de la Revolución cubana), implicarían la reestructuración de las guerrillas liberales en comunistas.

El Frente Nacional se proyectó entonces a finales de la década del cincuenta como una salida a esa situación de confrontación entre liberales y conservadores, conocida en Colombia como la Violencia. Con el fin de lograr la paz y consolidar un orden, los partidos acuerdan relevarse en el ejercicio del gobierno del Estado y distribuirse por partes iguales los cargos burocráticos. Así, el pacto frentenacionalista significó el cierre de la participación política a solo estas dos colectividades. Ciudadanos y corrientes de pensamiento distintas no tenían forma ni oportunidad de acceder y participar del poder.

En el Frente Nacional se identifican una serie de restricciones democráticas, como la paridad en la división del poder del Estado entre liberales y conserva-

2 Los primeros grupos insurgentes nacen como reacción a los abusos estatales. En sí, se desarrollaron como guerrillas liberales que tenían como fin defender sus derechos, esto para aclarar que en su origen no tenían una influencia ideológica marcada y doctrinaria como el comunismo. 
40 | Uso bélico de las normas penales en Colombia (1962-1980):

arma estatal para derrotar al enemigo

dores, dejando por fuera del pacto a otros movimientos políticos y sociales. De esta manera, la dificultad de acceder al poder por fuera de los partidos tradicionales propició el surgimiento y consolidación de grupos subversivos, ya que las guerrillas surgen ante la exclusión de otras formas e ideas diferentes frente a la concepción del Estado, es decir, frente "al bloqueo sistemático a la consolidación de fuerzas políticas diferentes al bipartidismo" (Sánchez, 2009, p. 35), además de la falta de oportunidades políticas para la otra parte de la población que se encontraba fuera del pacto frentenacionalista, que, en últimas, recogía en su gran mayoría los intereses de las élites políticas del país.

Si bien uno de los factores que propiciaron la creación de este pacto fue la inconformidad existente en el país frente a la dictadura militar de Rojas Pinilla, hay quienes sostienen que el acuerdo frentenacionalista fue "la prolongación de la dictadura, ya no militar, sino civil, pues el pacto dejaba por fuera de la vida política a los partidos y a las personas no adscritas al liberalismo o al conservatismo" (Mesa, 2009, p. 159).

En este contexto, la guerra interna se convertiría en la principal fuente del derecho penal —que define básicamente el componente bélico de las normas penales-, lo cual haría de él un "instrumento represivo carente de racionalidad" (Cote, 2010). De hecho, ya el Estatuto de Seguridad, expedido durante el gobierno de Turbay (Decreto 1923 de 1978), en la antesala del Código Penal de 1980, es un ejemplo de las medidas que se adoptarían frente a la amenaza percibida o definida en un momento específico por la política criminal o la política penaß ${ }^{\beta}$. Asuntos como la defensa nacional y el restablecimiento del orden público se convirtieron en la justificación para implementar normas penales usadas para hacer la guerra a los enemigos construidos en el período y despejar cualquier duda sobre la firmeza del Estado para combatirlos.

Aunque en esos mismos años muchos Estados latinoamericanos reaccionaron de formas más o menos similares frente al comunismo, especialmente después del triunfo de la Revolución cubana, en el caso colombiano se destacó la asimilación

3 En el desarrollo de este artículo se llegó a la conclusión de que política criminal debería ser asumida como sinónimo de política penal, porque a ambas se les vincula al ejercicio de poder político que se transforma y refleja en las normas penales. Si se le da una connotación muy amplia al término de política criminal, no sería posible, ni sencillo, la distinción frente a otras políticas como las sociales o las de seguridad. Es un asunto que refiere a elementos metodológicos para no crear dificultades y conflictos frente a las políticas que tienen un marco de actuación diferente y que son impulsadas por otros niveles institucionales. Por esto, se entenderá la política criminal como una categoría análoga a la de política penal. 
de cualquier forma de organización social por fuera de los partidos tradicionales como sinónimo de subversión; "entre la represión estatal y la radicalización de las guerrillas nacidas en los sesentas, en pleno Frente Nacional, se engendró la violencia que hoy azota el país" (Mesa, 2009, p. 177).

También Francisco Leal resalta que el triunfo de la revolución en Cuba propició la formulación de la Doctrina de Seguridad Nacional, que entre otras cosas convirtió a América Latina "en el campo para enfrentar una subversión considerada en los medios castrenses como parte de la Guerra Fría" (Leal, 2003, p. 79) y, como se sabe, dicha subversión no solo implicaba a los alzados en armas, sino también, como enseñaba un manual de formación militar, a

(...) movilizaciones, huelgas, aplicación de las ciencias sociales comprometidas, infiltración de escuelas y universidades. Todos estos mecanismos se tornan cada vez más sutiles, y el peligro se cierne sobre nosotros y nuestros seres más queridos. Tenemos una grave responsabilidad sobre nuestros hombros, la de combatir contra un enemigo que no se puede reconocer ni saber cuándo dará su golpe. (Sandoval, 1985, p. 91)

Por esto, uno de los efectos que se pueden reconocer de un país en conflicto como Colombia es que provoca un fraccionamiento, incluso una dislocación de la población, que tiende a impedir más que nunca su transformación en actor (Pécaut, 2015, p. 16) al punto que el Estado persiguió, solo por divergencias de orden político o ideológico, a sujetos que representaban formas e ideas diferentes a las de quienes controlaban el aparato coercitivo del Estado.

En ese marco de trastrocamientos o generalizaciones, las normas penales serían usadas con propósitos bélicos en lo que ha sido denominado como "derecho penal del enemigo". En este, hay una anticipación de las barreras de actuación del derecho penal a "un ámbito anterior de manera que ya la conducta anticipada se considera lesiva de un bien jurídico" (Polaino-Orts, 2007). La dinámica de esta forma de derecho sostiene que al menor indicio de peligrosidad o lesión al bien jurídico se deben tomar medidas preventivas que castiguen esas conductas.

Existen fuertes tensiones entre el derecho penal del enemigo y las garantías que deben imperar en el marco de un Estado de derecho - derecho penal del ciudadano-, en el que el ejercicio del poder de castigar del Estado está sometido al límite básico de la legalidad. El primer tipo de derecho no va dirigido a ciudadanos, sino a enemigos, es decir, el otro, al que se dirige, no es un ciudadano, sino un enemigo, una "no persona" inclusive (Jakobs, 2003). Las lógicas por las que se 
42 Uso bélico de las normas penales en Colombia (1962-1980):

arma estatal para derrotar al enemigo

rige esta actuación no son las del derecho, sino las de la guerra, pues al otro se le trata como si fuera un enemigo, y al derecho penal se le entiende como un arma. En el caso colombiano si bien se reconoce el uso bélico de las normas penales, la operatividad de la teoría del derecho penal de enemigo es cuestionable, ya que "la guerra no es una metáfora y las normas penales son usadas — en efecto- como medios para derrotar enemigos" (Muñoz, 2014, p. 159).

El enemigo emerge como la figura de quien representa una amenaza constante a su propio entorno, al cual se le restringen ciertos derechos debido a su peligrosidad. Como lo anota Schmitt, el enemigo tiene su propio estatus, no necesariamente es un criminal. A su vez, "la figura del enemigo podría especificarse cuando esta condición puede incluir normalmente representaciones morales, estéticas o sentimentales, pero que no dejan de ser contingentes para la constitución de la enemistad" (Giraldo, 1999, p. 136). El contrario o enemigo también puede significar la representación de una condición que se reconoce como indeseable, amenazante y problemática.

Entender la política al modo de Schmitt, partiendo de que "la relación amigoenemigo marca el grado máximo de intensidad de una unión o separación, de una asociación o disociación” (Schmitt, 2009, p. 57), significa asumir el conflicto como la relación fundante y la dinámica propia en la que se desenvuelven las relaciones entre el Estado y quienes hacen parte de él, entendiendo que la guerra ingresa en el dominio de la política y se manifiesta como "fundadora de orden, como fundamento y principio de la soberanía, como justificación moral del Estado y del derecho, como manera de ponerle fin a los estados de belicosidad" (Uribe, 1998 p. 12). Una guerra o confrontación de larga duración como la que ha vivido Colombia ${ }^{4}$ se desenvuelve en un escenario donde se cuenta con una indefinición política en relación con el sujeto soberano (Pérez, 2000) dado que las disputas por el control de Estado enfrentan proyectos antagónicos, por lo que ha sido posible que "en regiones del territorio nacional se configuren órdenes alternativos de facto con pretensiones soberanas" (Uribe, 1998, p. 19). Es en un contexto turbado por la guerra y la inestabilidad política en el que emerge la figura del enemigo y el Estado, en aras de garantizar el control efectivo del territorio, considera la violencia y la fuerza como un mecanismo viable para eliminar esa

4 La guerra o confrontación armada interna es aquella que se desarrolla contra enemigos internos, esto es, cuando "el enemigo, el hostil, ya no es el extranjero que invade el territorio sino aquel capaz de afectar el orden social y desestabilizar el orden político" (Uribe, 2002, p. 127). 
figura indeseable y amenazante, que toma diversos rostros y que no se agota en los grupos guerrilleros como se verá posteriormente.

Esta forma de actuar del Estado, en la que la represión y la confrontación del enemigo también se hace mediante el uso bélico del derecho que busca el sometimiento de esos enemigos a un orden jurídico legal, se puede relacionar con el sistema de poder que Foucault llama la "guerra-represión", es decir, "la reaparición de la guerra en la escena pública, con todos sus desafíos al poder establecido; un campo de tensiones desequilibrado al cual se opondría la represión como manera de volver a unos mínimos niveles de equilibrio." (Uribe, 2002, p. 127). Así, el pretexto de la guerra sirve para que el Estado reestructure su discurso, actúe con firmeza y autoridad e identifique aquellos enemigos que amenazan su control y dominio.

En Colombia, aquella concepción que prioriza el uso bélico de las normas penales ha prevalecido por décadas, con la particularidad de que no ha resuelto ni mejorado ninguno de los problemas que pretendía enfrentar, sino que los ha intensificado (Aponte, 2006) Así, este tipo de medidas se han tomado para continuar la guerra por medios más civilizados, pero no propiamente más efectivos. Prueba de lo anterior es que después de más de cincuenta años el país aún sigue inmerso en una situación de conflicto y guerra: existen grupos armados que disputan la soberanía y obligan al Estado a desplazar todo tipo de recursos para hacerles frente, incluyendo dentro de estos recursos al derecho.

La construcción del enemigo no recayó solo en la otra parte que constituían, desde aquellos ańos setenta, los guerrilleros comunistas. También se catalogó como enemigos a sindicalistas, activistas, estudiantes, es decir, otros actores que no significaban precisamente una amenaza directa y que no participaban del conflicto armado, pero el Estado pretendió controlarlos porque los veía como "bases de apoyo - a la insurgencia - representadas en el ascenso de los movimientos sociales" (Uribe, 1995, p. 50). Esto puede resumirse como una experiencia negativa que significó el uso bélico del derecho como un arma política que continúa la guerra por otra vía diferente a la de las armas, que reprimió por medio de las normas a quienes se atrevían a lanzar críticas y cuestionamientos frente a las acciones estatales en diversos campos.

Por otro lado, el Estado de sitio fue una figura extraordinariamente recurrente entre los años 1962 y 1980. Esta es otra de las características que permiten advertir el uso bélico de las normas penales en el caso colombiano, pues si bien en Colombia no hubo golpes de estado, como sí los hubo en países como Argentina, 
Chile o Brasil, el discurso de la Doctrina de la Seguridad Nacional promovió el combate del enemigo interno incluso con el derecho.

Durante los años sesenta y setenta, hay entonces una legislación penal encaminada a la eliminación del enemigo. Un enemigo que en los años anteriores al Frente Nacional sería el "liberal ateo" y que a la postre tomaría cuerpo en el "guerrillero comunista". Después de los años ochenta, nuevamente el enemigo mutaría hacia el narcotraficante y, finalmente, estaría encarnado en la figura del terrorista. Una evolución que sintetiza de esta manera el profesor Julio González: "discursivamente se hace el relevo entre una violencia fratricida, nacida de la confrontación liberal-conservadora, a una violencia que viene desde ahora, que está dirigida no contra un partido determinado, sino contra la democracia, la civilización occidental y la cultura cristiana" (González, 2009).

En suma, las razones que justifican el uso bélico de las instituciones penales en Colombia son, en un primer momento, la realidad conflictiva del país, las frecuentes turbaciones del orden y las amenazas desafiantes al Estado. Por otro lado, encontramos el accionar autoritario del Estado frente a dichas situaciones. Apelar a la figura de estado de excepción recurrentemente sugiere la utilización del derecho como arma preventiva, con el que incluso se negaron derechos y libertades a los ciudadanos que no participaban en el conflicto armado como guerreros.

Otra característica de las instituciones penales de la época es que en la creación normativa no medió la discusión parlamentaria, sino que la legislación (más exactamente los decretos legislativos, los decretos con fuerza de ley o los decretos de facultades) sería directamente emitida por el poder ejecutivo (Aponte, 2006). La mayor parte de normas expedidas tenían como justificación "la conservación del orden público y su restablecimiento". La dinámica que adoptaron los gobiernos en las décadas de los sesenta y los setenta en Colombia corresponde a una época en la que el Congreso no tuvo mayor protagonismo en la construcción de este tipo de normas.

Se trató de una legislación que quiso responder a una coyuntura específica de crisis - frente a quienes se definió como enemigos del orden constitucional y democrático. Esta respuesta por parte del ejecutivo limitó ciertas garantías bajo el pretexto de perseguir al enemigo, y el Congreso no vio problemas en revestir de manera recurrente al ejecutivo de facultades extraordinarias, cediendo su principal función constitucional, la de crear la ley, al ejecutivo. 
En este sentido y teniendo en cuenta los aspectos definidos anteriormente, varios gobiernos han optado por la posibilidad de convocar comisiones que involucran expertos en ciertas materias para que hagan diagnósticos y recomendaciones como resultado de sus estudios, esto es, las comisiones de expertos tienen entre sus funciones: asesorar con base en los estudios realizados de manera especializada a las autoridades encargadas de diseñar políticas; como lo sostiene Rodrigo Uprimny, las comisiones de expertos han logrado establecer vasos comunicantes entre el mundo académico y la política pública, y esto en algún sentido le es útil a los hacedores de políticas (Uprimny, 2015).

Además, los expertos normalmente formulan recomendaciones con fundamento en los saberes que integran sus campos de formación académica. En este sentido, el caso colombiano no ha sido una excepción, y en los inicios del Frente Nacional se convocó una comisión a la que se le conoce como la Investigadora, una de las primeras comisiones organizadas con este propósito, con el fin de que hiciera un diagnóstico de las causas presentes de la violencia en el país.

\section{Los expertos hacen recomendaciones: ¿fueron atendidas sus propuestas?}

En un país que se ha visto afectado por la violencia durante tanto tiempo, y cuyos gobiernos reconocen públicamente a unos enemigos, como ya se ha resaltado, también se optó por darle a personajes con trayectoria académica y conocimiento del conflicto 5 la tarea de estudiar e identificar las causas de la violencia, permitiéndoles hacer recomendaciones para diseñar estrategias con el fin de acabar la situación de violencia y con sus responsables.

La Comisión Investigadora de las Causas y Situaciones Presentes de la Violencia fue una comisión de expertos creada en el mes de mayo de 1958 con el fin de realizar el estudio y análisis del país. Sin embargo, esta comisión estuvo conectada, desde su gestación, a medidas de emergencia ya bastante usuales en la historia del país (Jaramillo, 2011). La comisión dio por concluida su labor en enero de

5 Los expertos son sujetos especializados, como mínimo, en un área de conocimiento. Tienen elementos que les permiten indagar y reflexionar sobre cuestiones en cierta materia -en este caso la política-y son figuras a las que regularmente recurre el gobierno para elaborar recomendaciones en torno a temas polémicos y sensibles de la sociedad. 
46 | Uso bélico de las normas penales en Colombia (1962-1980):

arma estatal para derrotar al enemigo

1959 arguyendo el cumplimiento de sus tareas, que había dejado de ser necesaria, y que sus miembros se mostraban agotados.

Según Jaramillo Marín, la Comisión fundó su relato en tres tramas narrativas. La primera de ellas supondría que nunca hubo un comienzo claramente establecido, lo que supone que Colombia es un país que históricamente se ha encontrado en conflicto. Por otra parte, "posiciona una narrativa de diagnosis acerca de un presente turbado por la guerra y cuyo paliativo son los decretos y estrategias de emergencia" (Jaramillo, 2011). Esto último se ve reflejado en las normas que, con la autorización del Congreso para el momento —antes del año 1962_, habían sido proferidas por los gobiernos como respuesta a los problemas de orden público.

De esta manera lo referencian en el libro La Violencia en Colombia, en dos tomos, que, vale la pena aclarar, es el texto académico que recoge las recomendaciones y el diagnóstico de los integrantes de la Investigadora de 1958, en el que exponen que uno de los problemas en torno a los decretos de emergencia es:

La irresponsabilidad parlamentaria, la pérdida o inexistencia de vínculos entre elector y elegido, el régimen de arbitrariedad en la interpretación de la voluntad pública, la falta de condicionamiento de la representación al cumplimiento de normas, han convertido al parlamento en un órgano suelto, dislocado, sin vida democrática. Por eso ha ido perdiendo el juego propio dentro del Estado, actuando sin órbita, en un riguroso movimiento pendular: o subordinándose al Gobierno -entregando su facultad legislativa por medio de "autorizaciones extraordinarias". (Guzmán, Umaña y Fals Borda, 1977)

El diagnóstico muestra las medidas implementadas en el estado de excepción por parte del poder ejecutivo como una constante. Para dar fin al sectarismo político y la situación de violencia, no solamente se han utilizado en Colombia medidas drásticas para castigar ciertas conductas. Como lo ilustra la Comisión, instituciones como el indulto y la amnistía fueron usadas frente a ciertos delitos de carácter político.

Si bien se ha señalado la dureza y la excepcionalidad recurrente en la forma de actuación del Estado en cuanto al uso bélico de las normas penales, también se debe resaltar que en ocasiones se ha buscado — para la rendición efectiva del enemigo- métodos más indulgentes en el trato de ciertos crímenes, porque se reconoce que estas acciones tienen una justificación política. 
Sin embargo, al referirse a las causas del conflicto en Colombia, la Investigadora hizo especial referencia a la impunidad y otras fallas de la justicia; además, resalta la dureza a la hora de impartir la fuerza por parte del Estado, lo que hace referencia explícitamente al uso bélico del derecho, con el que incluso agentes ajenos a la administración de justicia hicieron uso de ella, impartiendo castigo:

Durante la Violencia se sobrepasó el límite legal para imponer penalidades, aspecto este que hizo más odioso cuando en su totalidad se implantaron por sujetos ajenos a los menesteres de la justicia y, casi siempre, en su calidad de funcionarios del orden administrativo, en franco accionar punitivo contra grupos de "rebeldes" o “enemigos en el orden público". (Guzmán, Umaña y Fals, 1977)

El Estado colombiano, lejos de acatar y considerar las recomendaciones ${ }^{6}$ del diagnóstico de los expertos, siguió optando por la vía de la coerción para dar fin a la violencia y las amenazas al orden. Esto fue algo que siguió evolucionando, y es paradójico, cuando ya se habían considerado amnistías e indultos, y según los expertos de la comisión, "esto funcionaba no como mecanismo de salvación de los criminales, sino como instrumentos de la paz social y política" (Guzmán, Umaña y Fals, 1977). Aunque también reconocieron que, como era propio de un país en conflicto, el país tendría que habituarse al tratamiento excepcional de ciertos actos violentos y sus responsables.

Sin embargo, lejos de superarse los episodios de violencia y sangre, el conflicto se agudizó y se consideraron necesarias medidas como el Estatuto de Seguridad de Turbay. Esta resulta siendo una característica más de una legislación penal en Colombia "donde la respuesta ante la desilusión social es la emisión de más y más normas." (Aponte, 2006), incluso de aquellas como el Decreto 541 de 1976, que es una muestra fehaciente de la naturaleza restrictiva y punitiva de las normas colombianas para la época:

ARTÍCULO 1. Quienes, reunidos tumultuariamente, perturben el pacífico desarrollo de las actividades sociales, realicen reuniones públicas sin el cumplimiento de los requisitos legales, obstaculicen el tránsito de personas o vehículos en vías públicas, escriban o coloquen leyendas o dibujos ultrajantes en lugar público o

6 Si bien en el apartado transcrito del libro "La Violencia en Colombia" no catalogan explícitamente como recomendaciones, desde su lectura y estudio sí se pueden inferir como tales, es decir, además del diagnóstico, existe un esfuerzo por brindar recomendaciones al Estado sobre el diseño de la política criminal. 
abierto al público, inciten a quebrantar la ley o a desobedecer la autoridad, desobedezcan orden legítima de autoridad, u omitan sin justa causa prestar el auxilio que esta le solicite incurrirán en arresto inconmutable hasta de ciento ochenta (180) días. (Decreto 541 de 1976)

El Decreto 541 de 1976 ilustra cómo se usa bélicamente la legislación en materia penal. Bajo esta lógica, manifestaciones del derecho de la asociación son consideradas punibles. Este tipo de prácticas por parte del Estado también busca - de manera indirecta - prevenir conspiraciones que perjudiquen la imagen y la legitimidad del gobierno, y no solamente esto, también se refleja cierto temor por un levantamiento en contra del orden y de la autoridad.

Normas de este tipo se pueden considerar una violación de derechos y libertades ciudadanas. Por ello Uribe (1995) sugiere que el estado de guerra permanente "permitió a los gobiernos de turno elaborar un discurso sobre el gran peligro que se cernía sobre la sociedad colombiana y, desde allí, diseñar estrategias de gobernabilidad que no estaban orientadas específicamente a derrotar al enemigo guerrillero" (p. 49). La figura del estado de sitio y la criminalización de la protesta social y de las reclamaciones por parte de diversos grupos sociales sirvieron como estrategias de gobernabilidad para un Estado cuya soberanía estaba en disputa durante este periodo, no solamente por los enemigos alzados en armas, también por aquellos que se atrevían a criticar las medidas y políticas gubernamentales y a reclamar un nuevo orden, todo esto se dio en un contexto de confrontación armada.

En el mismo sentido, el Decreto 070 de 1978, por medio del cual se legalizaba la muerte de personas, ilustra el uso bélico del derecho arriba enunciado. Veamos:

ARTÍCULO 1. Mientras subsista turbado el orden público y en estado de sitio todo el territorio nacional, el artículo 25 del Código Penal quedará así:

ARTÍCULO 25. El hecho se justifica cuando se comete:

(...)

4o. Por los miembros de la fuerza pública cuando intervengan en operaciones planeadas para prevenir y reprimir los delitos de extorsión y secuestro, y producción, procesamiento y tráfico de estupefacientes. (Decreto 070 de 1978)

Como se observa, el numeral cuatro faculta a los miembros de la fuerza pública — militares y policía - a prevenir y, si es el caso, reprimir conductas que se consi- 
deran delictivas o peligrosas, incluso causando la muerte de los presuntos infractores (incluidos los subversivos no armados). Además, estas facultades son atribuidas por parte del ejecutivo a la fuerza pública en el marco de un estado de sitio.

Para ilustrar más la situación, en el Estatuto de Seguridad de 1978 se castigaba la presión a autoridades legítimas, incitación a desobedecer órdenes de autoridad, uso injustificado de máscaras, porte injustificado de objetos — como piedras o tacos- y colectas con destino a actividades ilegales. La imposición de un castigo muestra cómo el Estado se adelanta — por medio de una norma penal—a una posible actuación delictiva, que en este caso corresponde a acciones que resultan peligrosas para el Estado, que considera necesario para conjurar el peligro castigar, así el delito no se haya materializado.

Por su parte, en el Código Penal de 1980 se incluye el delito de terrorismo —otra forma de representación del enemigo-, que cometen quienes, "con el fin de crear o mantener un ambiente de zozobra, o de perturbar el orden público, empleen contra personas o bienes medios de destrucción colectiva. Diez a veinte años de prisión sin perjuicio de la pena que corresponda por los demás delitos que ocasionen este hecho" (artículo 187 del CP). De esta forma, se puede constatar la manera en que la fuerza de la norma penal se constituye en un arma con la que cuenta el Estado para eliminar o doblegar al enemigo que se combate, endureciendo el trato no solo mediante la fuerza, también mediante un discurso más fuerte y directo.

Vale la pena mencionar que, si bien inicialmente se quiso analizar la incidencia del diagnóstico de la Investigadora de 1958 en torno al diseño de la política criminal, en el transcurso de la investigación se pudo apreciar la incidencia de otro tipo de recomendaciones de expertos en todo un código penal. Se trató del Código Penal de 1980, que fue fruto del trabajo de las comisiones redactoras en los años 1972 y $1978^{7}$. El Decreto Ley 416 de 1972 dispuso el establecimiento de una comisión redactora que tuviera como proyecto la creación de un nuevo código penal, mientras que la Ley 5 de 1979, expedida por el Congreso, concedió facultades extraordinarias al presidente con el fin de

7 Este es un hallazgo que se dio en el transcurso de la investigación, gracias a la que se pudo cotejar que en la elaboración del Código Penal de 1980 fue efectiva la incidencia de los expertos en su redacción y diseño. 
(...) expedir y poner en vigencia un nuevo Código Penal, sobre las bases, principios y lineamientos generales del proyecto presentado por el Gobierno al Senado de la República el 3 de agosto de 1978 y el anteproyecto publicado en 1974 por el Ministerio de Justicia, y para los efectos de esta Ley formará parte del expediente. (Ley 5 de 1979)

El anteproyecto de la comisión redactora fue implementado en su totalidad por el Gobierno, lo que representa una incidencia directa de los expertos en el diseño de la política criminal, en este caso con la expedición de Código Penal de 1980, que, aunque recogiera la recomendación experta, seguía manteniendo la lógica del uso bélico de las normas penales. Entonces, si bien ha sido documentado a lo largo de este texto la poca incidencia del diagnóstico y recomendaciones de la Investigadora de 1958 en el diseño de la política criminal, es necesario resaltar que el Código Penal de 1980 sí recoge efectivamente el proyecto presentado por la comisión redactora de 1972, aunque las normas siguieran siendo drásticas y la presencia del enemigo sigue vigente en ellas bajo figuras diversas, como la del terrorista mencionada anteriormente, reafirmando la búsqueda incesante del Estado para castigar y reprimir a aquellos grupos ilegales que le disputan la soberanía y ponen en juicio su papel efectivo como garante de los derechos de la sociedad civil.

La figura del enemigo en las instituciones penales en Colombia no es una simple metáfora; al contrario, el enemigo se personifica en todo aquel al que el Estado considera como peligroso. Esto revela un país donde ha existido una relación estrecha e incuestionable entre guerra, derecho y política. Así, la "guerra" y la figura del enemigo no responden a simples metáforas en el contexto colombiano (González, 2009), donde efectivamente sí hay una situación de guerra y un enemigo detectado: "La lógica de la guerra se entiende de una manera alarmante y cada vez invade más espacios de la vida social y política” (Blair, 1995, p. 67).

La estrecha relación entre guerra, derecho y política, como sugiere Muñoz (2014), es una confirmación de las fallas estructurales — no solo del Estadosino de la sociedad colombiana, en cuanto a la tramitación de sus diferencias y el ejercicio mismo de los derechos y libertades de sus ciudadanos, en la que se prioriza la fuerza y se posterga el diálogo en la búsqueda de soluciones a la situación de crisis que significa el estado de guerra.

El derecho, además de constituir un arma política y de convertirse en la "vestidura del Estado en la guerra" (Iturralde, 2003), bajo la cual este se apoya para eliminar a sus enemigos y representar su poder, también ha estado provisto de 
una fuerte carga simbólica que legitima la acción estatal ante la opinión pública. Esto es lo que Mauricio García Villegas (1991) reconoce como "la presentación de las normas jurídicas como símbolos dirigidos hacia la representación, donde se enfatiza la fuerza del derecho, en su carácter de discurso" (p. 20). De esta manera, es difícil negar la relación entre la guerra, el derecho y la política en el contexto colombiano, donde el uso bélico de las normas penales se constituye en una de las armas por medio de las cuales el Estado combate a sus enemigos y se legitima ante una opinión pública que reclama resultados en el combate a la subversión y persecución a la delincuencia.

En síntesis, muchos de los delitos a los cuales el Estado ha aplicado este tipo de normas surgen del estado de guerra, inseguridad y violencia que ha permeado el país a lo largo del siglo XX. Las guerrillas, el narcotráfico y el terrorismo son fenómenos que han tenido un desarrollo paralelo a la guerra en el país y la única respuesta del Estado frente a esta situación de crisis ha sido la represión a través "del endurecimiento y militarización del sistema penal y la concesión de amplios poderes a las fuerzas militares y de seguridad" (Iturralde, 2003, p. 33). Lo problemático de esta cuestión es que se pueden llegar a excesos tales que se pueden ver vulnerados los derechos más básicos y las libertades más elementales.

Por ejemplo, el Decreto 2066 de 1977 estableció restricciones a la libertad de información:

ARTÍCULO 1. Mientras subsista el actual estado de sitio, por las estaciones de radiodifusión sonora y por los canales de televisión no podrán transmitirse informaciones, declaraciones, comunicados o comentarios relativos al cese de actividades o a paros y huelgas ilegales. (Decreto 2066 de 1977)

Este tipo de restricciones también son repercusiones propias de una legislación autoritaria y drástica, en un contexto de orden amenazado. Así es como funciona el derecho en cuanto herramienta política para contrarrestar el daño que le causa el enemigo a la imagen del Estado. Esto es propio en un país de violencias que se transforman y reciclan, donde los instrumentos excepcionales siempre resultan herramientas privilegiadas por los ejecutivos. (Jaramillo, 2011). La práctica de la política por medio de la guerra y la violencia fue utilizada para conseguir "beneficios colectivos y equilibrios sociales o para impedir manifestaciones de descontento por demandas insatisfechas" (Uribe, 1995 p. 48), cuya finalidad estuvo encaminada a garantizar unos mínimos de gobernabilidad por parte del Estado colombiano. 
52 | Uso bélico de las normas penales en Colombia (1962-1980):

arma estatal para derrotar al enemigo

A su vez, el Decreto 1923 de 1978, o Estatuto de Seguridad, afirmaba lo siguiente:

ARTÍCULO 7: Se impondrá arresto inconmutable hasta por un año a quien o quienes:

a) Ocupen transitoriamente lugares públicos, o abiertos al público, u oficinas de entidades públicas o privadas, con el fin de presionar una decisión de las autoridades legítimas, o de exhortar a la ciudadanía a la rebelión.

b) Inciten a quebrantar la ley o a desobedecer a las autoridades o desatiendan orden legítima de autoridad competente.

c) Usen injustificadamente máscaras, mallas, antifaces u otros elementos destinados a ocultar la identidad o alteren, destruyan u oculten las placas de identificación de los vehículos.

d). Porten injustificadamente objetos utilizables para cometer infracciones contra la vida e integridad de las personas, tales como armas de fuego, puñales, cuchillos, machetes, varillas, tacos, piedras, botellas con gasolina, mechas, sustancias químicas o explosivos.

En este nuevo ejemplo se puede observar la criminalización de diversas conductas, al punto de llegar a castigos desproporcionados frente a conductas como el porte de piedras o el uso de objetos como los antifaces, que imposibilitan el reconocimiento de una persona. De esta manera "se utilizó entonces, la rígida lógica militar de la oposición amigo-enemigo, para crear el concepto de enemigo interno, transformando al adversario político en enemigo" (Leal, 2003, p. 84), llegando a excesos tales en la lógica del uso bélico del derecho de castigar prácticas propias de la protesta social y de criminalizar los diferentes repertorios con que cuenta la movilización social, como el porte de piedras o el uso de máscaras.

Todo lo anterior contrasta con una de las recomendaciones del diagnóstico de la Comisión Investigadora de 1958 en la se resaltaba que, ante la situación de violencia en Colombia, se estaba sobrepasando el límite legal para imponer penalidades, y los gobiernos siguientes adoptaron medidas que continuaban este tipo de prácticas en las que el uso bélico de las normas penales es evidente, además de la criminalización de las formas tradicionales de protesta social.

Como se puede notar, el Estado construye las crisis y define como criminal, y puntualmente como "subversivo", tanto a quienes se levantan en armas contra el régimen como quienes se comportaran de manera crítica al Gobierno (Art. 1 del 
Decreto 1923 de 1978). Este tipo de medidas busca ampliar el campo de maniobra para un Estado que ve amenazado su dominio y en peligro su gobernabilidad, llegando al punto de castigar por medio del derecho, es decir, de las normas penales, posturas críticas o contrarias al Gobierno legalmente constituido.

Además, el estado de sitio fue una figura que se constituyó como "el remedio para todos los males, en todo momento" (Pérez, 1999). La situación de violencia que supone una amenaza para cualquier Estado - y Colombia no es una excepción- hizo recurrente la figura del estado de sitio, mediante el que se toman una serie de decisiones políticas que facultan al Gobierno para restringir ciertos derechos y libertades en tanto se restablezca el orden. Además, "el estado de excepción, asumido como estrategia de gobernabilidad, no se aplicó solamente al campo del orden público, sirvió también para tomar algunas decisiones sobre política económica, reformas institucionales y legislación penal." (Uribe, 1995, p. 50), dinámica que Melo califica de banal, irritante y permanente (2010).

En este sentido, como afirma Pérez, "la figura del estado de sitio en un telón de fondo de perturbación permanente y de utilización exacerbada del estado de excepción como exclusivo recurso de gobernabilidad" (1999) significó una herramienta política propia del régimen colombiano para legitimarse y garantizar su dominio ante la amenaza que suponía la figura del enemigo que tanto he mencionado ${ }^{8}$.

Si bien la Comisión advirtió lo problemático de que el poder legislativo pierda protagonismo dentro del Estado al delegar, recurrentemente, al Gobierno central su principal función, la facultad legislativa, por medio de lo conocido como "autorizaciones extraordinarias", práctica que se siguió presentando a lo largo del tiempo, como se puede observar en el siguiente ejemplo:

LEY 27 DE 1963: Por la cual se reviste al Presidente de la Republica de facultades extraordinarias, de acuerdo con el numeral 12 del artículo 76 de la Constitución Nacional.

8 El estado de excepción se convirtió, por lo menos hasta 1991, en un instrumento ordinario de la política gubernamental. La excepción era casi permanente. Así, por ejemplo, en los 21 años transcurridos entre 1970 y 1991 Colombia vivió 206 meses bajo estado de excepción, es decir, 17 años, lo cual representa el 82\% del tiempo transcurrido. Entre 1949 y 1991 Colombia vivió más de 30 años bajo estado de sitio. (El Espectador, 2008) 
ARTÍCULO 1. De conformidad con el numeral 12 del Artículo 76 de la Constitución Nacional, revístese al Presidente de la República de facultades extraordinarias hasta el 20 de julio de 1964, para los efectos siguientes:

1. Para reorganizar la Rama Jurisdiccional del Poder Público y el Ministerio Público. En tal virtud, el Presidente de la República podrá:

a. Atribuir plena competencia a los Jueces Municipales en materia civil, penal y laboral, limitando la de los Jueces Superiores al conocimiento de los siguientes delitos, en cuyo juzgamiento debe intervenir el Jurado:

2. Traición a la Patria.

3. Delitos que comprometan la paz, la seguridad exterior o la dignidad de la Nación.

4. Piratería, rebelión, sedición, asonada.

5. Asociación para delinquir.

La consecuencia política — quizá la más seria- es que el poder ejecutivo se convierte en el creador de la ley, siendo esta otra de las prácticas que persistieron a pesar del diagnóstico de la comisión investigadora de 1958. La creación de la ley —y más la ley penal— suponía una facultad del Congreso, sin embargo, "de haberse dado su discusión habrían sido aprobadas con dificultad y en un proceso legislativo sumamente lento, lo cual no se justificaba mientras existiera un recurso constitucional expedito como el estado de sitio" (Uribe, 1995, p. 50), que además se explicaba por la situación conflictiva del país, lo que permitió usar - como se ha mostrado - de manera bélica las instituciones penales.

Como se mencionó anteriormente, un rasgo que podríamos definir como característico de las administraciones del Estado en Colombia durante el periodo comprendido entre los años 1962 y 1980 ha sido el trato punitivo al fenómeno de la violencia. Y bien lo plantearon los expertos en la Investigadora: la idea no es perdonar y olvidar lo que hacen los criminales, se trató también de mostrar un trato más benévolo como gesto de paz y de reconciliación. Esto supone que es el soberano quien sigue teniendo la capacidad de decisión sobre los enemigos a combatir, para lo cual puede incluso recurrir a los mecanismos excepcionales dispuestos para ello (Martínez, 2009).

De esta forma, se debe tener en cuenta que la resolución de una situación de violencia generalizada haciendo un uso bélico del derecho cierra la puerta al campo de la sociabilidad, es decir, a la oportunidad de construir espacios favorables para pensar en el otro, en el oponente o contradictor político, pues ve en los conflictos únicamente actos criminales y la imagen amenazante del enemigo. 
Esto favorece los referentes socioculturales que "están enmarcados por la imagen del enemigo y cuya expresión más visible es el recurso permanente a las armas como el mecanismo privilegiado de relación con el otro" (Blair, 1995, p. 68), precisando que el derecho, específicamente la legislación penal, también ha posibilitado la construcción de la otredad y las estrategias para contenerla.

En síntesis, es válido pensar que las recomendaciones establecidas por los expertos en la década de los sesenta propendían por el entendimiento de la política como relación y consenso, lo que implica cambiar la imagen del enemigo como condición indispensable para la búsqueda de soluciones políticas (Blair, 1995, p. 71). No obstante, el Estado privilegió el uso bélico de las normas penales para enfrentar al enemigo y en general para afrontar la situación de violencia generalizada que vivió el país, sin que ello implicara una mayor efectividad para tramitar exitosamente los conflictos.

\section{Conclusiones}

Se puede concluir que la violencia fue un elemento fundante y transversal en el desarrollo de la legislación penal en Colombia en el periodo comprendido entre 1962 y 1980. En las respuestas que el Estado diseñó se puede advertir un continuum entre guerra y derecho, en lo que se ha denominado como el uso bélico del derecho. El tratamiento mismo que el Estado colombiano le ha dado a sus crisis destaca el estado de sitio, por encima de otros puntos de vista que sugieren un diálogo articulado entre las ramas del poder público para que el ejecutivo no asuma las facultades propias del legislativo.

A pesar de las dudas sobre las repercusiones de las comisiones de expertos en la toma de decisiones del Estado frente a la política criminal, se puede $-\mathrm{y}$ es válido - plantear que efectivamente sus recomendaciones pueden tener efectos, como se advirtió al observar el documento final proporcionado por la comisión redactora del Código Penal de 1980, que el Gobierno adoptó en su totalidad al expedir el Decreto-Ley 100 de 1980. La convocatoria de expertos es una práctica recurrente por parte del Estado y se sigue implementando, ya que se considera oportuno reunir a los expertos para que se estudien coyunturas y temas sensibles y luego hagan diagnósticos y recomendaciones al respecto (Uprimny, 2015).

Por otra parte, la figura del enemigo ha sido relacionada por el Estado colombiano no solamente con los liberales, ateos, guerrilleros, narcotraficantes y 
56 | Uso bélico de las normas penales en Colombia (1962-1980):

arma estatal para derrotar al enemigo

terroristas, sino también en los activistas, sindicalistas y estudiantes. Esto sugiere un trato bélico a la movilización social a través de las instituciones penales. Es decir, la protesta y la inconformidad social fueron criminalizadas, lo que amplía el margen de actuación y control del Estado sobre sus ciudadanos y, de esta forma, intenta garantizar para sí unos mínimos de gobernabilidad.

Cuando se revisan algunas de las normas penales expedidas en el periodo de 1962-1980, se convalida la hipótesis que sostiene que el Estado colombiano respondió ante las crisis con decretos que restringieron derechos y libertades, justificándose con un estado de cosas turbado y un ambiente político conflictuado que, ante todo, amenazaba la gobernabilidad del ejecutivo. Ante tal estado de cosas el Estado privilegió la criminalización de los conflictos sociales.

Por último, si bien este texto se refiere al pasado, ojalá sirviera como una reflexión para que tales prácticas políticas no se repitan. En un contexto de negociación para terminar políticamente el conflicto armado como el que hoy vive Colombia, es válido pensar una reformulación frente a las barreras de actuación del Estado por vía del derecho penal. Esto sugiere que la respuesta a los problemas del país no debe ser solamente de tipo bélico y punitivo.

En conclusión y a la manera de Chantal Mouffe, "el comportamiento agonal, lejos de representar un peligro para la democracia, es en realidad su condición misma de existencia" (Mouffe, 1999, p. 16), en la que la relación con el otro no debe suponerse ni desarrollarse en un contexto que siga implicando antagonismos. Por el contrario, este tipo de relaciones deben darse en términos agónicos, en la que la figura del otro represente la imagen de un adversario, contradictor u oponente, y no un enemigo tal como lo presenta Schmitt.

\section{Referencias bibliográficas}

Aponte, A. (2006). Guerra y política: dinámica cotidiana del derecho penal del enemigo. Medellín: Nuevo Foro Penal.

Blair, E. (1995). La imagen del enemigo. ¿un nuevo imaginario social? Estudios Políticos, 6, 47-71.

Cote, G. (2010). Derecho penal de enemigo en la Violencia (1948-1966). Bogotá: Pontificia Universidad Javeriana.

Decreto Legislativo 541 de 1976. Diario Oficial Nro. 34530, Presidencia de la República, Bogotá, 13 de abril de 1976.

Decreto Legislativo 070 de 1978. Diario Oficial Nro. 34944, Presidencia de la República, Bogotá, 1 de febrero de 1978. 
Decreto Legislativo 416 de 1972. Acta Nro. 83, Presidencia de la República, Bogotá, 31 de octubre de 1972.

Decreto Legislativo 2066 de 1977. Diario Oficial Nro. 34874, Presidencia de la República, Bogotá, 23 de septiembre de 1977.

Decreto Legislativo 1923 de 1978. Diario Oficial Nro. 35101, Presidencia de la República, Bogotá, 6 de septiembre de 1978.

Decreto Legislativo 100 de 1980. Diario Oficial Nro. 31461, Presidencia de la República, Bogotá, 20 de febrero de 1980.

Ley 27 de 1963. Diario Oficial Nro. 31189, Congreso de la República, Bogotá, 24 de septiembre de 1963.

Fals, O. (1977). La violencia en Colombia. Tomo I. Bogotá: Punta de Lanza.

Giraldo, J. (1999). Los otros, que no son el enemigo. Situación polémica y terceros en Schmitt, Freud y Bobbio. Estudios Políticos, 14, 135-148.

García, M. (1991). La eficacia simbólica y narcotráfico en Colombia. En: Las drogas bajo tres nuevos enfoques analíticos: de la narcodiplomacia y la simbología jurídica a la industria del placer (pp. 18-40). Bogotá: Centro de Estudios Internacionales de la Universidad de los Andes.

González, J. (2009). La política criminal en Colombia o cómo se construye un enemigo. En A. Calle (compilador), El estado actual de las ciencias penales. Medellín: Grupo Editorial Ibáñez.

Goodin, R. (2003). Teoría del diseño institucional. Barcelona: Gedisa.

Iturralde, M. (2003). Guerra y derecho en Colombia: el decisionismo político y los estados de excepción como respuesta a la crisis de la democracia. Estudios Sociales, 15, 29-46.

Jaramillo, J. (2011). Las comisiones de estudio sobre la violencia en Colombia: tramas narrativas y ofertas de sentido temporal para comprender la violencia. México: Clacso.

Jakobs, G. y Cancio, M. (2003). Derecho penal del enemigo. Madrid: Civitas.

Levi, M. (1990). Una lógica de cambio institucional. En: The Limits of Rationality (pp. 402-419). Chicago: Universidad de Chicago.

Martínez, W. (2009). La dictadura como encarnación de lo político: anotaciones en torno a Carl Schmitt. Estudios Políticos, 34, 47-62.

Melo, J. (2010). Los límites del poder bajo el Frente Nacional. Texto leído en el Seminario 50 año de regreso a la democracia. Nuevas miradas a la relevancia histórica del Frente Nacional, Universidad de los Andes, Bogotá, p. 1-10.

Mesa, E. (2009). El Frente Nacional y su naturaleza antidemocrática. Estudios de Derecho, 29 (110), 157-184.

Muñoz, J. (2014). Derecho y contexto: algunos problemas del derecho en Colombia en relación con el derecho constitucional, el derecho penal y el derecho privado. Estudios de Derecho, 71 (158), 147-167.

Mouffe, C. (1999). El retorno de lo político: comunidad, ciudadanía, pluralismo, democracia radical. Barcelona: Paidós.

Pécaut, D. (2015). Un conflicto armado al servicio del status quo social y político. En Comisión Histórica del Conflicto y sus Víctimas, Contribución al entendimiento del conflicto armado en Colombia. Bogotá.

Pérez, W. (1999). Sistema penal y emergencia en Colombia. Revista de Geografía y Ciencias Sociales, 45.

Pérez, W. (2000) Guerra y delito en Colombia. Estudios Políticos, 16, 11-41. 
58 | Uso bélico de las normas penales en Colombia (1962-1980):

arma estatal para derrotar al enemigo

Polaino-Orts, M. (2007). Derecho penal del enemigo. ¿Qué es? ¿Existe? ¿Debe existir? ¿Por qué existe? Bogotá: Derecho Penal y Sociedad.

Puerta, C. (2008). Discurso político y violencia en Colombia o cómo se construye un enemigo 1949-1980. Estudios de Derecho, 65 (145), 189-220.

Un país de estado de excepción. (11 de octubre de 2008). El Espectador. Recuperado de http://www.elespectador.com/impreso/politica/articuloimpreso43317-un-pais-deestados-de-excepcion.

Schmitt, C. (2009). El concepto de lo político. Madrid: Alianza Editorial.

Sandoval, E. (1985). Sistema penal y criminología crítica. Bogotá: Temis.

Sánchez, G. (2009). Colombia, violencia y democracia. Medellín: La Carreta Histórica.

Uribe, M. (1995). Crisis política y gobernabilidad en Colombia 1980-1995. Estudios Políticos, 8, 39-59.

Uribe, M. (1998). Las soberanías en vilo en un contexto de guerra y paz. Estudios Políticos, 13, 11-37.

Uribe, M. (2002). La guerra y la política: una mirada desde Michel Foucault. Estudios Políticos, 20, 123-136.

Vásquez, L. (2009). La abducción como alternativa del método científico en la educación superior. Uni-pluri/versidad, 8 (2), 1-12. 